\title{
THE QUANTITATIVE PALEOBIOGEOGRAPHY OF DINOSAURS
}

WEISHAMPEL*, David B., Department of Cell Biology and Anatomy, The Johns Hopkins University School of Medicine, Baltimore, MD 21205, U.S.A.;

CHAPMAN, Ralph E., Applied Morphometrics Laboratory, ADP NHB MRC 136, National Museum of Natural History, Smithsonian Institution, Washington, DC 20560, U.S.A.

Paleobiogeographic analyses of dinosaurs tend to be anecdotal because of the rare and fragmentary nature of most of their remains and because of difficulties in collecting adequate data. However, a recent comprehensive compilation of dinosaur occurrences, world-wide and throughout the Mesozoic, has made it possible to examine the distribution of that group quantitatively for the first time.

Using an updated version of this compilation, we have analyzed the distribution of the Dinosauria using standard approaches of quantitative paleobiogeography. The data used are the presence/ absence of taxa for localities. The analytical methods used included graphical approaches, clustering methods, and ordinations. Taxonomic level was varied from the genus level to higher groupings based on internal nodes on a working cladogram for the whole Dinosauria, roughly equivalent to the higher taxonomic levels (e.g., family) used in other such studies. The level of the locality data also was varied from single ones (e.g., Montana or Southern England in the Upper Cretaceous) to more clumped groupings (e.g., England, Western United States in the Late Jurassic).

From the presence/absence data we generated similarity matrices for both the taxa and localities using a variety of coefficients that differ in how they treat missing data. This allowed us to examine the relationships of the taxa based on their occurrences among the localities, and examine the relationships of the localities based on the taxa they contain. The results were quite informative and useful, although the nature of fossil record for dinosaurs makes this the first in an anticipated series of studies done as more material is collected and identified, and as the taxonomic relationships are refined. The temporal and geographic distribution of the localities was clearly evident in the results; e.g., Upper Cretaceous localities grouped together with geographically expected subclusters. The higher-level clustering within these temporal groups also was very informative, showing regional biogeographic relationships. The analyses of the taxa also provided useful insights into their associations, again with a very distinct time element forming the major clusters and different geographic associations forming the subclusters. Low level analyses produced more detailed information but suffered from less stability in the results and more anomalous OTUs, especially single localities or taxa that do not seem related to anything. Higher level (more clumped) studies were much more stable and easy to interpret, and provided useful information, but, in places, lacked the detail provided by the lower-level analyses. 